\title{
The pregnane xenobiotic receptor, a prominent liver factor, has actions in the midbrain for neurosteroid synthesis and behavioral/neural plasticity of female rats
}

\author{
Cheryl A. Frye $e^{1,2,3,4,5,6,7 *}$, Carolyn J. Koonce ${ }^{1,6,7}$ and Alicia A. Walf ${ }^{1,6,7}$ \\ 1 Department of Psychology, The University at Albany-SUNY, Albany, NY, USA \\ 2 Department of Biological Sciences, The University at Albany-SUNY, Albany, NY, USA \\ ${ }^{3}$ The Center for Neuroscience Research, The University at Albany-SUNY, Albany, NY, USA \\ ${ }^{4}$ The Center for Life Sciences Research, The University at Albany-SUNY, Albany, NY, USA \\ ${ }^{5}$ Department of Chemistry and Biochemistry, The University of Alaska-Fairbanks, Fairbanks, AK, USA \\ ${ }^{6}$ Institute of Arctic Biology, The University of Alaska-Fairbanks, Fairbanks, AK, USA \\ 7 IDeA Network of Biomedical Excellence (INBRE), The University of Alaska-Fairbanks, Fairbanks, AK, USA
}

\section{Edited by: \\ Mikhail Lebedev, Duke University, USA}

\section{Reviewed by:}

Raúl G. Paredes, National University of Mexico, Mexico

Mikhail Lebedev, Duke University, USA

Graziano Pinna, University of Illinois at Chicago, USA

Nico Mitro, Università degli Studi di Milano, Italy

\section{*Correspondence:}

Cheryl A. Frye, Department of Chemistry and Biochemistry, Institute of Arctic Biology, The

University of Alaska-Fairbanks, 223 Murie Life Sciences Building, 982

Koyukuk Drive, Fairbanks, AK

99775, USA

e-mail: cheryl.a.frye@gmail.com
A novel factor of interest for growth/plasticity in the brain is pregnane xenobiotic receptor (PXR). PXR is a liver factor known for its role in xenobiotic clearance and cholesterol metabolism. It is expressed in the brain, suggesting a potential role for plasticity, particularly involving cholesterol-based steroids and neurosteroids. Mating induces synthesis of neurosteroids in the midbrain Ventral Tegmental Area (VTA) of female rodents, as well as other "plastic" regions of the brain, including the hippocampus, that may be involved in the consolidation of the mating experience. Reducing PXR in the VTA attenuates mating-induced biosynthesis of the neurosteroid, $5 \alpha$-pregnan$3 \alpha-o l-20-o n e(3 \alpha, 5 \alpha-\mathrm{THP})$. The $18 \mathrm{kDA}$ translocator protein (TSPO) is one rate-limiting factor for $3 \alpha, 5 \alpha$-THP neurosteroidogenesis. The hypothesis tested was that PXR is an upstream factor of TSPO for neurosteroidogenesis of $3 \alpha, 5 \alpha$-THP in the VTA for lordosis, independent of peripheral glands. First, proestrous rats were administered a TSPO blocker (PK11195) and/or 3 $\alpha, 5 \alpha$-THP following infusions of PXR antisense oligonucleotides (AS-ODNs) or vehicle to the VTA. Inhibiting TSPO with PK11195 reduced $3 \alpha, 5 \alpha$-THP levels in the midbrain and lordosis, an effect that could be reversed with $3 \alpha, 5 \alpha$-THP administration, but not AS-ODN $+3 \alpha, 5 \alpha-$ THP. Second, proestrous, ovariectomized (OVX), or ovariectomized/adrenalectomized (OVX/ADX) rats were infused with a TSPO enhancer (FGIN 1-27) subsequent to AS-ODNs or vehicle to the VTA. PXR AS-ODNs blocked actions of FGIN 1-27 for lordosis and $3 \alpha, 5 \alpha$-THP levels among proestrous $>$ OVX $>$ OVX/ADX rats. Thus, PXR may be upstream of TSPO, involved in neurosteroidogenesis of $3 \alpha, 5 \alpha$-THP in the brain for plasticity. This novel finding of a liver factor involved in behavioral/neural plasticity substantiates future studies investigating factors known for their prominent actions in the peripheral organs, such as the liver, for modulating brain function and its augmentation.

\section{Keywords: midbrain ventral tegmental area, allopregnanolone, progesterone, cognition, reproduction}

\section{INTRODUCTION}

Steroid hormones are well-recognized for their role for growth processes in the body. For example, physiological roles of steroids hormones for growth are apparent during puberty, with the onset of the patterned secretion of these steroids from the gonads, and morphological differences (secondary sex characteristics), and during pregnancy, with substantial changes in many systems modulated by steroid hormones (e.g., the progestogensprogesterone and its metabolites), as two examples. In these two examples there are obvious physical changes, but the effects, mechanisms, and brain targets of steroids, such as the progestogens, for cognitive and behavioral processes, in relation to the body, are starting to become better understood. Data from large clinical trials conducted of hormone replacement therapies
(HRTs) (which typically include synthetic compounds to mimic hormones lost during menopause, estradiol and progesterone), do not entirely support the basic literature on the beneficial role of these hormones for brain functions, like enhancements in learning/memory (described below) and reduction in strokeand injury-related pathology (Roof et al., 1992, 1993; Chen et al., 1999; He et al., 2004; Shapiro, 2006; Billeci et al., 2007). Moreover, these trials were halted early due to increased cardiovascular and cancer risks and there was a subsequent backlash against clinical use of HRTs that did not take into account individual patient characteristics and risk (Rossouw et al., 2002; Shumaker et al., 2003; Maki and Henderson, 2012). Together, these examples substantiate the importance of understanding the role and mechanisms of steroids in the body and brain. 
In addition to the controversy of whether the potential benefits of hormones outweigh their risks, there has been controversy of the role of progestogens for benefiting brain function per se. Historically, the basic experimental design to understand whether a particular hormone was necessary and sufficient for a physiological process was to assess co-variation in the hormone of interest and a process and remove the gland that produced the hormone (extirpation) and replace back the hormone (to see if the process is abrogated and then reinstated, respectively). In rodent models of cognitive function, studies assessing natural increases in progestogens over the estrous cycle, or during and after pregnancy, support the mnemonic effects of these high, physiological levels of progestogens in spatial and object recognition tasks (Lambert et al., 2005; Walf et al., 2006; Kinsley and Lambert, 2008; Paris and Frye, 2008; Macbeth and Luine, 2010). Moreover, ovariectomy (surgical removal of the ovaries) of young, adult female rats produces performance deficits in the object recognition and placement tasks, which can be abrogated with replacement back with progesterone or its neuroactive metabolite, $5 \alpha$-pregnan-3 $\alpha$ ol-20-one ( $3 \alpha, 5 \alpha$-THP, a.k.a. allopregnanolone; Walf et al., 2006; Frye et al., 2007). However, these beneficial effects of progestogens are not uniformly observed in other studies, using different tasks, or dosing and formulation of progestogens, or involving investigations in aged rodents (Murphy et al., 2002; Toung et al., 2004; see review by Acosta et al., 2013). Together, these data suggest that progestogens' effects for cognitive function may be influenced by task, dosing and formulation of progestogen administered, age and likely many other factors.

Given that there are many factors that can influence responses to progestogens for neural processes, an approach that we have taken is to use the well-characterized behavioral model of reproductive behavior of rodents to investigate progestogens' mechanisms. The notion is that we can begin to understand the mechanisms of progestogens in regions that have been investigated for decades (hypothalamus and midbrain) for this basic, hormone-dependent behavior (lordosis, or mating posture of female rodents), substantiating subsequent studies on such mechanisms in corticolimbic structures underlying complex cognitive processes. Lordosis only occurs in appropriate neuroendocrine and environmental context, with reductions in the response supported by effects of ovariectomy, steroid blockers or environmental stressors (Uphouse et al., 2005, 2013; reviewed in Frye, 2011; Frye et al., 2013). From studies using this approach, the effects of progesterone and/or its metabolite, $3 \alpha, 5 \alpha$-THP, in the midbrain ventral tegmental area (VTA), through novel neurotransmitter targets (e.g., GABA, dopamine, glutamate, and second messenger cascades) have been supported (reviewed in Frye and Walf, 2008). Interestingly, there is high expression of factors involved in the metabolism and synthesis of $3 \alpha, 5 \alpha$-THP in the VTA (from precursor of all steroids, cholesterol; reviewed in Frye, 2011), suggesting the importance of $3 \alpha, 5 \alpha-$ THP production and action in this region.

Another consideration is that experience can alter hormone levels (and thereby modify the CNS). An example of this is mating-induced neurosteroid synthesis. Mating induces synthesis of neurosteroids in the midbrain VTA of female rodents, as well as other "plastic" regions of the brain, including the hippocampus and prefrontal cortex, that may be involved in the consolidation of the mating experience in rodents. There can be dynamic changes in $3 \alpha, 5 \alpha$-THP production in midbrain and corticolimbic structures following mating or other social and environmental challenges (Purdy et al., 1991; Barbaccia et al., 2001; Agís-Balboa et al., 2007; Pinna et al., 2008; Pinna and Rasmusson, 2012). In further support, midbrain $3 \alpha, 5 \alpha$-THP levels are higher after female rats are tested in the paced mating task, compared to standard mating task (which does not involve females temporally controlling the frequency of contacts with males), compared to no mating (reviewed in Frye, 2011). Thus, our model system is to use lordosis as a bioassay to further understand mechanisms involved in $3 \alpha, 5 \alpha$-THP synthesis and actions for neural/behavioral plasticity.

Studies focused on mechanistic questions about progestogens' actions and production in the VTA, using lordosis as the bioassay, have been extended to understand novel targets, such as the pregnane xenobiotic receptor (PXR), for these responses. PXR has a well-established role as a ubiquitous and promiscuous nuclear receptor in the liver and other excretory organs (kidneys, intestines) for metabolism and xenobiotic clearance (Geick et al., 2001; Dussault and Forman, 2002; Francis et al., 2002; Kliewer et al., 2002). Its role in the CNS was not understood until more recently. Some of the first studies examining PXR's role were those focused on its function in the blood-brainbarrier, which was similar to other excretory organs in the body (Bauer et al., 2004, 2006; Xu et al., 2005; Harmsen et al., 2007; Ma et al., 2008; Zhang et al., 2008; Ott et al., 2009). However, PXR is also expressed in the brain itself, suggesting a potential role for plasticity, particularly involving steroids (which are cholesterol-based hormones) and neurosteroids (which are produced from metabolism of cholesterol in the central nervous system itself). For example, for synthesis of $3 \alpha, 5 \alpha$-THP, cholesterol is transported into the mitochondria by way of the $18-\mathrm{kDa}$ translocator protein (TSPO) on the outer mitochondrial membrane. Inside the mitochondria, cholesterol interacts with steroidogenic acute regulatory protein and cytochrome P450-dependent side chain cleavage (P450scc) enzymes (Mellon and Deschepper, 1993; King et al., 2002; Papadopoulos et al., 2006), as well downstream steroidogenic enzymes ( $5 \alpha$-reductase, $3 \alpha$-hydroxysteroid dehydrogenase) to produce pregnenolone, progesterone, dihydroprogesterone, and, ultimately, $3 \alpha, 5 \alpha$-THP. A question is the role of PXR in this pathway. Our interest in PXR as a novel target was supported by a microarray study in which the gene for this receptor was expressed in the midbrain following paced mating of female rodents (reviewed in Frye, 2011). We subsequently characterized the expression of this receptor in the midbrain across the estrous cycle of rats (in which we found higher expression associated with higher progestogen levels; Frye et al., 2012, 2013). Moreover, knocking down PXR expression in the VTA reduces mating-induced biosynthesis of $3 \alpha, 5 \alpha-$ THP in the VTA. Given that TSPO is one rate-limiting factor for $3 \alpha, 5 \alpha-$ THP neurosteroidogenesis, a question is whether metabolism at TSPO involves, or requires, PXR for production of $3 \alpha, 5 \alpha$-THP. The hypothesis was that PXR is a necessary upstream factor of TSPO for neurosteroidogenesis of $3 \alpha, 5 \alpha$-THP in the VTA for lordosis, independent of peripheral glands. We assessed the role of 
PXR, and TSPO manipulations in different hormonal contexts (i.e., over the estrous cycle with extirpation of the ovaries and/or adrenal glands). First, proestrous rats were administered a TSPO blocker (PK11195) and/or 3 $\alpha, 5 \alpha$-THP following infusions of PXR antisense oligonucleotides (AS-ODNs) or vehicle to the VTA in Experiment 1. We aimed to determine the extent to which the TSPO inhibitor may have effects similar to PXR knockdown and whether this may be reversed with $3 \alpha, 5 \alpha$-THP replacement. Second, proestrous (Experiment 2), ovariectomized (OVX; Experiment 3), or ovariectomized/adrenalectomized (OVX/ADX; Experiment 4) rats were infused with a TSPO enhancer (FGIN 127) subsequent to AS-ODNs or vehicle to the VTA. We aimed to determine the extent to which the TSPO enhancer may reverse effects of PXR knockdown and whether this may be related to hormonal milieu. Results from these experiments supported the notion that PXR (traditionally considered a liver factor), may be upstream of TSPO, acting as a homeostatic regulator involved in neurosteroidogenesis of $3 \alpha, 5 \alpha$-THP in the brain and behavioral plasticity.

\section{MATERIALS AND METHODS SUBJECTS AND HOUSING}

Adult, Long-Evans female rats $(n=236)$, approximately 55 days of age, were bred in the Life Sciences Laboratory Animal Care Facility at The University at Albany-SUNY (original stock: Taconic Farms, Germantown, NY, USA) and/or shipped from Taconic. Rats were group-housed in polycarbonate cages with woodchip bedding $(45 \times 24 \times 21 \mathrm{~cm})$ in a temperature$\left(21 \pm 1^{\circ} \mathrm{C}\right)$ and humidity- $(50 \pm 5 \%)$ controlled room in the Laboratory Animal Care Facility. Rats were maintained on a 12:12 h reversed light cycle (lights off at 0800 hours) with continuous access to Purina Rat Chow and tap water in their home cages.

\section{GENERAL PROCEDURE}

Four experiments were run, using a between- and within-subjects design. All experimental rats had stereotaxic surgery to implant cannulae aimed at the VTA, 7 days before drug manipulations were initiated. Experimental rats were randomly-assigned to one treatment condition (between-subjects) within a single experiment, and then were tested in a single battery of behavioral tasks (within-subjects). The general procedure utilized is depicted in Figure 1. All experimental techniques in rats were approved by the Institutional Animal Care and Use Committee at the University at Albany, where the experiments were conducted.

\section{SURGICAL MANIPULATIONS}

All rats in Experiments 1-4 were stereotaxically implanted with bilateral guide cannulae aimed at the VTA (from bregma: $\mathrm{AP}=-5.3, \mathrm{ML}= \pm 0.4, \mathrm{DV}=-7.0$; Paxinos and Watson, 1986) under xylazine $(12 \mathrm{mg} / \mathrm{kg})$ and ketamine $(80 \mathrm{mg} / \mathrm{kg})$ anesthesia per prior methods (Frye et al., 2013). Immediately following stereotaxic surgery, rats were OVX $(n=49$; Experiment 3$)$ and/or OVX/ADX ( $n=48$; Experiment 4$)$. For OVX/ADX, dorsal incisions were made between the ribs and hip, so that the ovaries and the adrenals could be isolated. The ovaries were ligated and removed, and the adrenals were isolated and removed. As ADX rats are sodium deficient, all rats received a bottle of $0.9 \%$ saline and a bottle of tap water in their home cages to maintain water/salt balance. Following surgery and prior to testing, animals were monitored for loss of weight, righting response, flank stimulation response, and/or muscle tone. Only rats that passed neurological evaluations and gained weight following surgery until behavioral testing commenced were continued in the experiment. All rats that underwent $\mathrm{ADX}$ were validated to have complete ADX surgery via post-hoc assessment of corticosterone in plasma. Rats were administered ibuprofen (once per oral, and daily in

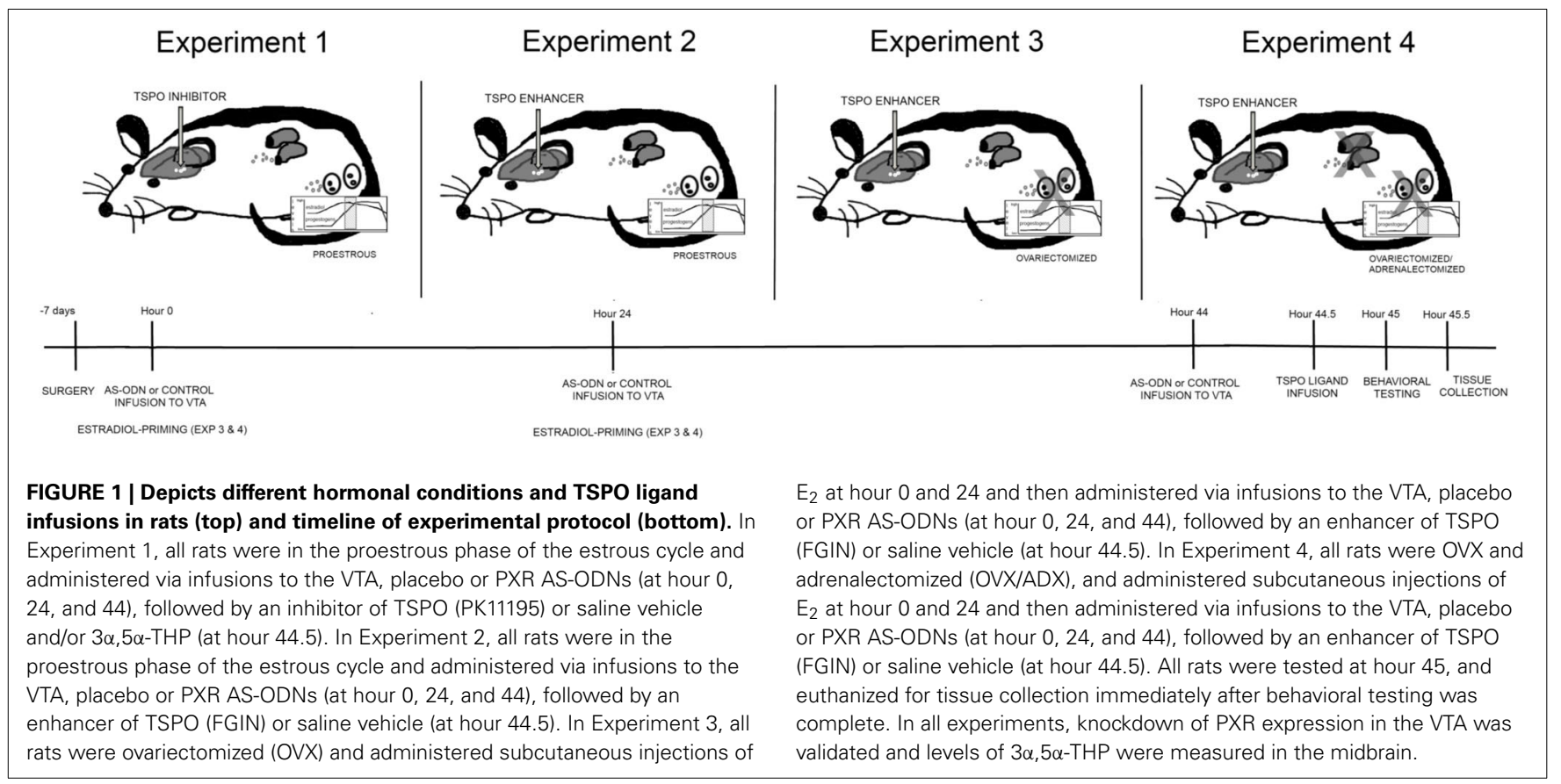


the recovery period in drinking water; $30 \mathrm{mg} / \mathrm{kg}$ ) as post-surgical analgesia.

\section{ESTROUS CYCLE}

Vaginal epithelium of each rat was collected and examined daily under a light microscope (between 0800-1000). Rats were cycled through two normal estrous cycles (4-5 days cycle) prior to testing. Rats were tested on proestrus (epithelium characterized by nucleated cells, $4-5$ days after the previous occurrence) for Experiments $1(n=68)$ and $2(n=71)$.

\section{INFUSIONS}

For Experiments 1-4, rats received either sterile saline $(0.9 \% \mathrm{w} / \mathrm{v})$ or PXR AS-ODN infusions. AS-ODNs by $\left(5^{\prime}\right.$ CTTGCGGAAGGGGCACCTCA $3^{\prime}$; made in a concentration of 100 ng/ $\mathrm{ll}$; Frye et al., 2012, 2013, 2014, in press) were synthesized and desalted Invitrogen Life Technologies (Carlsbad, CA). This PXR AS-ODN strategy decreases expression of PXR in the midbrain, as measured by quantitative polymerase chain reaction (qPCR) (which was utilized here to validate) and western blotting (Frye, 2011; Frye et al., 2012, 2013). In Experiment 1, PK11195 (Tocris Biosciences, R\&D Systems, Minneapolis, MN) was utilized as a TSPO antagonist (compounded by adding crystalline drug to sterile saline at a concentration of $50 \mathrm{ng}$

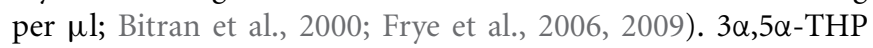
(purchased from Dr. Robert Purdy, Scripps Institute, CA) was prepared to a concentration of 100 ng per $\mu \mathrm{l}$ in $\beta$-cyclodextran (with $5 \%$ concentration of $\beta$-cyclodextran in sterile water; Frye and Rhodes, 2006; Frye et al., 2008a, 2014). In Experiments 2-4, a neurosteroidogenesis enhancer, FGIN 1-27, an agonist of TSPO was utilized (Petralia and Frye, 2005; Frye et al., 2009, used in Experiments 2-4). Crystalline FGIN was compounded in a concentration of $50 \mathrm{ng}$ per $\mu \mathrm{l}$ (Tocris) in sterile saline. Rats received bilateral infusions of each compound or placebo vehicle. This infusion protocol has been utilized without any indication of damaging effects as assessed by behavioral changes, or estradiol levels (given damage can induce aromatase activity, and thereby local estradiol levels; Azcoitia et al., 2003); this was determined by comparing rats that were sham surgerized, had stereotaxic implantation of cannulae to the VTA, but were not administered infusions, and those that were administered infusions of saline vehicle in the same volumes as drugs are administered (Frye et al., 2013).

\section{ESTRADIOL PRIMING}

For Experiment 3 and 4, OVX and OVX/ADX rats were primed with subcutaneous administration of estradiol $(10 \mu \mathrm{g}$ in $0.2 \mathrm{cc}$ vegetable oil) at 0 and $24 \mathrm{~h}$ before behavioral testing.

\section{BEHAVIORAL MEASURES}

Our primary interest was in the role of PXR and TSPO for reproductive responding (as measured in the paced mating task); however, control measures of exploration, anxiety, and social interaction were also collected. Behavioral data were simultaneously collected by using the Any-maze behavioral assessment computer program (Stoelting Inc., Wood Lawn, IL; for open field, elevated plus maze, and social interaction) or a digital video camera (for paced mating) and trained experimenters.

\section{Control measures- exploration, anxiety, non-sexual social interaction}

Immediately before assessment in the paced mating task, rats were tested sequentially in the open field for $5 \mathrm{~min}$, the elevated plus maze for $5 \mathrm{~min}$, and the social interaction tasks, as per established methods (see Frye et al., 2013). Across experiments, there were no differences between comparisons groups in rats that were tested for exploratory behavior in the open field, anxiety behavior in the elevated plus maze, or social interaction with a female conspecific.

\section{Paced mating}

Paced mating was conducted per previous methods (Erskine, 1985; Frye et al., 2013) in an apparatus $(37.5 \times 75 \times 30 \mathrm{~cm})$ that was divided down the center by a Plexiglas partition. An experimental female has access to both sides of the pacing chamber, while a stimulus male was confined to one side for a $15-\mathrm{min}$ test period. Standard measures of mating behavior (lordosis quotients, proceptivity quotients, and aggression quotients) are being reported herein. Lordosis quotients are the percentage of total number of lordosis responses per total number of sexual contacts by the male. Aggression/rejection (aggression quotients) are defined as behaviors such as boxing and kicking the male during contacts.

\section{TISSUE COLLECTION AND PREPARATION}

Immediately after testing, rats were euthanized by rapid decapitation and whole brain and trunk blood was collected, frozen, and stored in a freezer. For brain dissections, punches from the midbrain, around the VTA, were taken from coronal frozen slices (approximately 60 microns thick), made anterior and posterior to the VTA, and used for analyses of PXR expression (described below). At this time of collecting these slices, whether cannulae/infusion tracks were aimed at the VTA was determined (as per Frye et al., 2013, 2014). There were a total of $n=17$ rats that had placement outside of the VTA; their data was excluded from analyses of the data from rats with placement to the VTA. Not all experimental groups were represented in rats that had missed sites, precluding systematic analyses of the data from these rats to those with placement to the VTA. However, in comparing the data available, the pattern that emerged was that rats with placement outside of the VTA had responses similar to control groups.

\section{VALIDATION OF PXR KNOCKDOWN FOLLOWING PXR AS-ODNs}

Standard qPCR methods were utilized on VTA punches to determine whether PXR AS-ODN infusions reduced PXR expression (described in Frye et al., 2013, 2014). Data were analyzed by comparing PXR values to actin control, and PXR expression is described as fold-change of the rats infused with PXR AS-ODNs to those infused with control (saline; Livak and Schmittgen, 2001; Schmittgen and Livak, 2008; Frye et al., 2013, 2014).

\section{STEROID HORMONE MEASUREMENT}

Plasma levels of corticosterone, estradiol, and progesterone were measured to validate adequacy of $\mathrm{ADX}$, estrous cycle stage and/or OVX and hormone-priming, respectively. Concentrations of corticosterone, estradiol, progesterone and $3 \alpha, 5 \alpha-\mathrm{THP}$ were assessed using standard steroid extraction and radioimmunoassay (primarily for corticosterone and $3 \alpha, 5 \alpha-\mathrm{THP}$ ) or 
commercially-available enzyme-linked immunosorbent assays (estradiol, progesterone) techniques used by our laboratory (Frye and Bayon, 1999; Frye et al., 2008a, 2013, 2014, in press). Concentrations were determined for each sample based upon concurrent standard curves run in duplicate for each of the assays. Concentrations reflect the approximate concentrations of the volume of plasma, or protein concentrations determined in midbrain homogenate samples measured by a NanoDrop spectrometer.

\section{STATISTICAL ANALYSES}

Analyses of variances (ANOVAs) were used to examine effects of PXR AS-ODN condition (control, PXR AS-ODN), PK11195 condition (control, PK11195) and $3 \alpha, 5 \alpha$,-THP condition ( $\beta$ cyclodextrin, $3 \alpha, 5 \alpha,-$ THP for Experiment 1) and for Experiment 2-4, PXR AS-ODN condition (control, PXR AS-ODN) and FGIN condition (control, FGIN), and/or testing condition (non tested, tested) on behavioral and endocrine measures. The assumptions of homogeneity of variance were supported, suggesting that parametric ANOVA tests be utilized as the most appropriate statistic across experiments. When the $\alpha$ level for statistical significance was reached ( $p=0.05$ ) for main effects and interactions, Fisher's Least Significant Differences post-hoc tests were used to determine group differences.

\section{RESULTS \\ EXPERIMENT 1: EFFECTS OF TSPO BLOCKER, PK11195, IN PROESTROUS RATS \\ Validation of PXR AS-ODNs for PXR expression in the midbrain}

Rats infused with PXR AS-ODN had 1.5 fold lower PXR expression in the midbrain VTA compared to rats infused with control condition $\left[F_{(1,29)}=11.9, P<0.001\right]$.

\section{$3 \alpha, 5 \alpha-$ THP levels in the midbrain (Figure 2A)}

There was significant interaction between PXR AS-ODN condition and $3 \alpha, 5 \alpha$-THP condition $\left[F_{(1,60)}=10.7, P<0.002\right]$ for $3 \alpha, 5 \alpha$-THP levels in the midbrain VTA, such that control rats infused with $3 \alpha, 5 \alpha$-THP had higher levels of $3 \alpha, 5 \alpha-$ THP levels in the midbrain compared to PXR AS-ODN infusions. There were significant main effects of PXR AS-ODN $\left[F_{(1,60)}=29.7, P<0.0001\right], 3 \alpha, 5 \alpha$-THP $\left[F_{(1,60)}=13.1, P=\right.$ $0.0007]$, and PK11195 $\left[F_{(1,60)}=7.3, P=0.01\right]$ conditions for $3 \alpha, 5 \alpha$-THP levels in the midbrain. Infusions of PXR AS-ODNs reduced, $3 \alpha, 5 \alpha$-THP increased, and PK11195 reduced $3 \alpha, 5 \alpha$ THP levels in midbrain compared to control infusions for each manipulation.

\section{Lordosis quotients (Figure 2B)}

There was an interaction between $3 \alpha, 5 \alpha$-THP condition and PK11195 condition $\left[F_{(1,60)}=11.4, P=0.001\right]$ for lordosis quotients, such that PK11195 reduced lordosis quotients, but not when co-administered with $3 \alpha, 5 \alpha$-THP. There was significant interaction between PXR AS-ODN condition and $3 \alpha, 5 \alpha-$ THP condition $\left[F_{(1,60)}=4.7, P=0.03\right]$ for lordosis quotients, such that control rats infused with $3 \alpha, 5 \alpha$-THP had increased lordosis quotients, but not when co-administered PXR AS-ODNs. There was a significant main effect of PXR AS-ODN

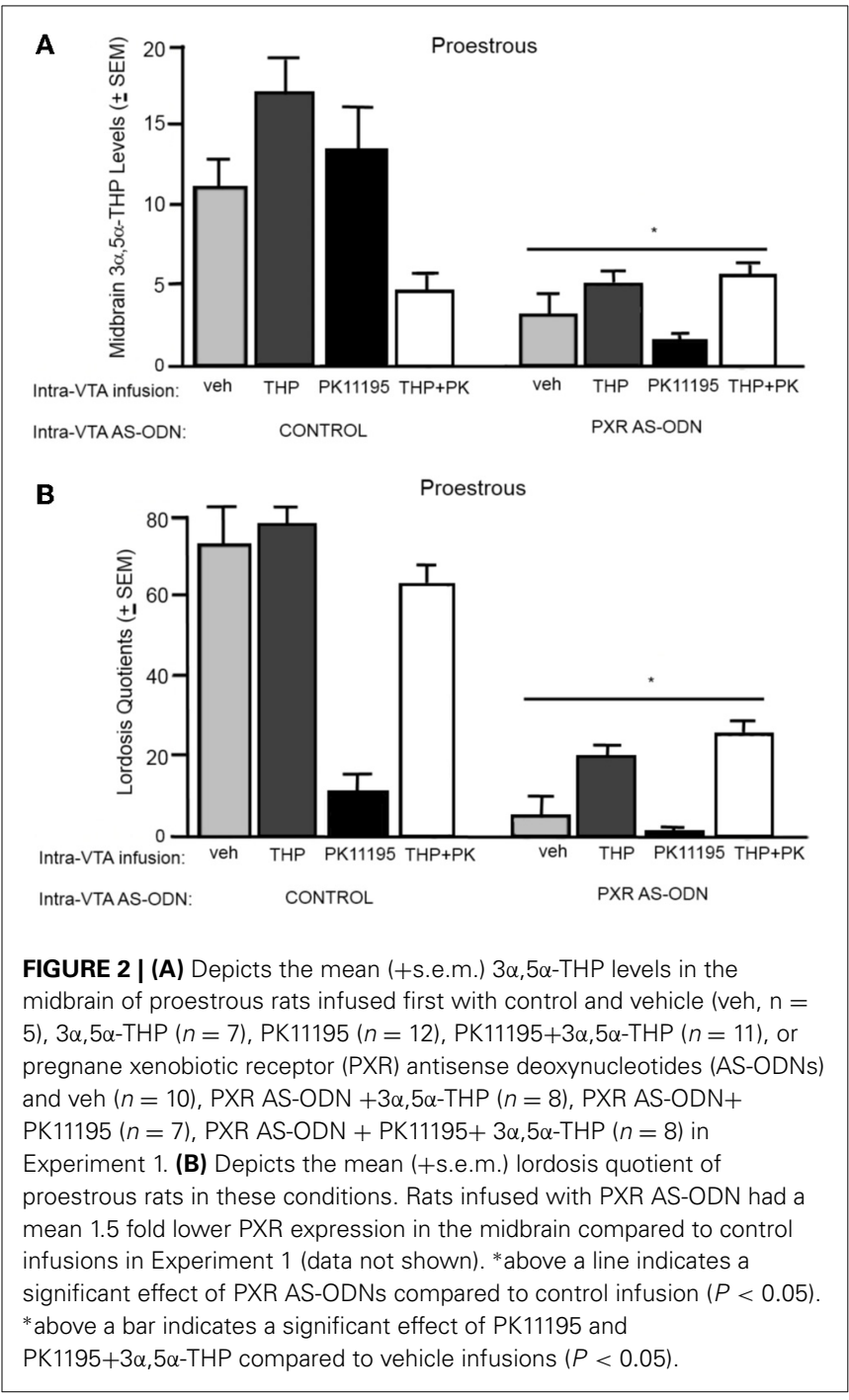

condition $\left[F_{(1,60)}=12.5, P=0.0008\right]$ to reduce lordosis quotients compared to those infused with control.

\section{Aggression quotients (Table 1)}

There was significant main effect of PXR AS-ODN condition $\left[F_{(1,60)}=19.9, P=0.0003\right]$ and PK11195 condition $\left[F_{(1,60)}=\right.$ 3.9, $P=0.05$ ] for aggression quotients. Rats infused with PXR AS-ODN or PK11195 had increased aggression quotients compared to respective control infusions.

\section{EXPERIMENT 2: EFFECTS OF TSPO ENHANCER, FGIN 1-27, IN PROESTROUS RATS}

\section{Validation of PXR AS-ODNs for PXR expression in the midbrain}

Rats infused with PXR AS-ODN had 1.8 fold lower PXR expression in the midbrain VTA compared to rats administered control infusions $\left[F_{(1,37)}=36.4, P<0.0001\right]$.

\section{$3 \alpha, 5 \alpha-$ THP levels in the midbrain (Figure 3A)}

There was a significant main effect of PXR AS-ODN condition $\left[F_{(1,52)}=14.4, P=0.0004\right]$ for $3 \alpha, 5 \alpha$-THP levels in the midbrain. Rats infused with PXR AS-ODN had significantly lower 
Table 1 | Depicts mean ( \pm s.e.m.) aggression quotients (AQ) of rats during the paced mating task In Experiments 1-4.

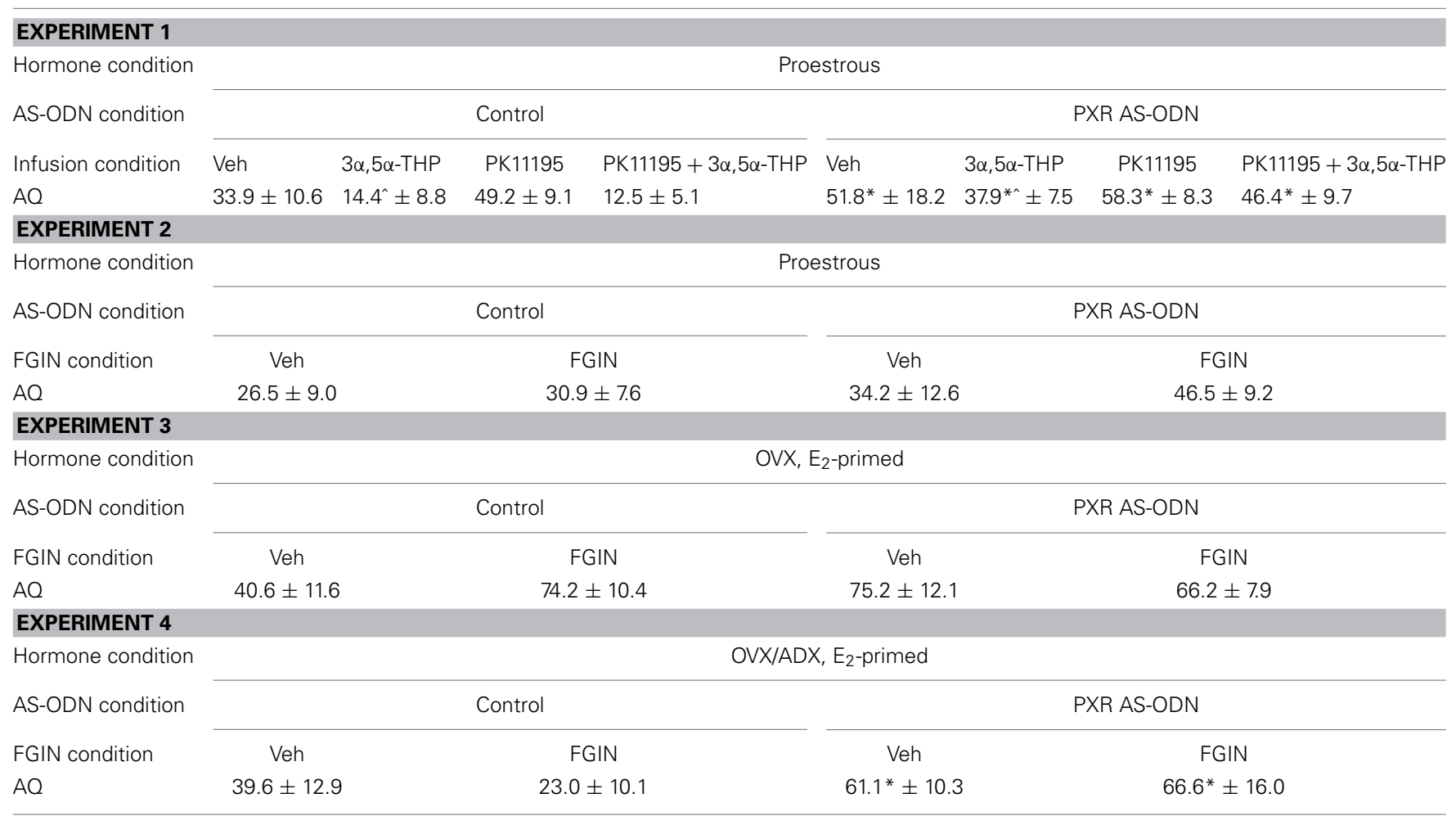

* Indicates a significant difference of pregnane xenobiotic receptor (PXR) PXR antisense oliodeoxynucleotides (AS-ODN) from control (P > 0.05).

^Indicates significant interaction between AS-ODN, PK11195, and $3 \alpha, 5 \alpha$-THP (P> 0.05).

$3 \alpha, 5 \alpha$-THP in the midbrain compared to those infused with control; effects of testing and FGIN infusions did not reach statistical significance.

\section{Lordosis Quotients (Figure 4A)}

There was a significant interaction between PXR AS-ODN condition and FGIN condition $\left[F_{(1,47)}=3.8, P<0.05\right]$ for lordosis quotients, such that PXR AS-ODNs reduced lordosis, but not when co-administered with FGIN. There was a significant main effect of PXR AS-ODN condition $\left[F_{(1,47)}=3.8, P=0.05\right]$ for lordosis quotients. Rats infused with PXR AS-ODN had significantly lower lordosis quotients compared to those infused with control condition.

\section{Aggression quotients (Table 1)}

There were no statistically significant effects of conditions for aggression quotients in this experiment.

EXPERIMENT 3: EFFECTS OF TSPO ENHANCER, FGIN 1-27, IN OVX RATS Validation of PXR AS-ODNs for PXR expression in the midbrain

Rats infused with PXR AS-ODN had 1.5 fold lower PXR expression in the midbrain VTA compared to control infusions $\left[F_{(1,41)}=14.2, P=0.0005\right]$.

\section{3 $\alpha, 5 \alpha-$ THP levels in the midbrain (Figure 3B)}

There was a main effect for testing condition $\left[F_{(1,41)}=16.9\right.$, $P=0.002$ ] for $3 \alpha, 5 \alpha$-THP levels in the midbrain, such that tested rats had higher levels of $3 \alpha, 5 \alpha$-THP inmidbrain compared to non-tested rats; effects of PXR AS-ODN and FGIN infusions did not reach statistical significance.

\section{Lordosis quotients (Figure 4B)}

There was a significant main effect of PXR AS-ODN condition $\left[F_{(1,24)}=18.9, P=0.0002\right]$ and FGIN condition $\left[F_{(1,24)}=9.3\right.$, $P=0.005]$ for lordosis quotients. Rats infused with PXR ASODN had significantly lower, and those infused with FGIN had significantly higher, lordosis quotients, compared to those infused with respective control conditions.

\section{Aggression quotients (Table 1)}

There were no significant main effects for AS-ODN condition or FGIN condition for aggression quotients.

\section{EXPERIMENT 4: EFFECTS OF TSPO ENHANCER, FGIN 1-27, IN OVX/ADX RATS \\ Validation of PXR AS-ODNs for PXR expression in the midbrain}

Rats infused with PXR AS-ODN had 1.4 fold lower PXR expression in the midbrain VTA compared to control infusions $\left[F_{(1,24)}=6.4, P=0.01\right]$.

\section{$3 \alpha, 5 \alpha-$ THP levels in the midbrain (Figure 3C)}

There was main effect of testing condition $\left[F_{(1,38)}=10.3, P=\right.$ $0.002]$ and PXR AS-ODN condition $\left[F_{(1,38)}=4.4, P=0.04\right]$ for $3 \alpha, 5 \alpha$-THP levels in the midbrain. Tested rats had higher levels of $3 \alpha, 5 \alpha$-THP in midbrain compared tonon-tested rats, and rats 
A

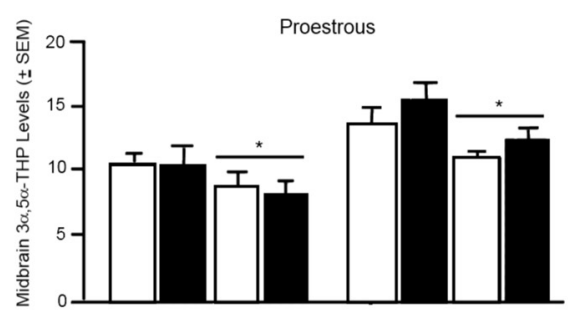

Intra-VTA Infusion: veh FGIN veh FGIN veh FGIN veh FGIN Intra-VTAAS-ODN: CONTROL PXRAS-ODN CONTROL PXRAS-ODN Testing Condition: NON-TESTED TESTED

\section{B}

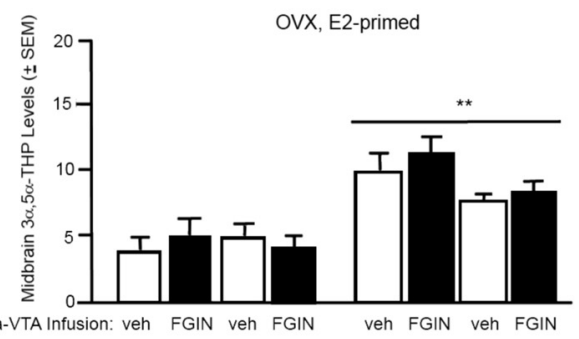

Intra-VTAAS-ODN: CONTROL PXRAS-ODN CONTROL PXRAS-ODN

Testing Condition: NON-TESTED TESTED

C

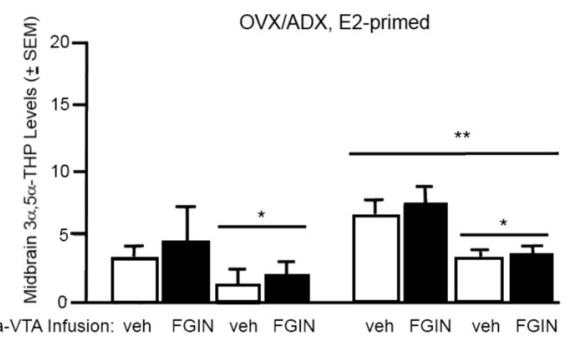

Intra-VTA Infusion: veh FGIN veh FGIN veh FGIN veh FGIN Intra-VTAAS-ODN: CONTROL PXRAS-ODN CONTROL PXRAS-ODN Testing Condition: NON-TESTED TESTED

FIGURE 3 | (A) Depicts the mean ( \pm s.e.m.) $3 \alpha, 5 \alpha$-THP levels in the midbrain of proestrous non tested rats infused with control and vehicle (veh, $n=5$ ) or control+FGIN $(n=4)$, or pregnane xenobiotic receptor (PXR) antisense deoxynucleotides (AS-ODNs) and veh $(n=6)$, or PXR AS-ODN+FGIN $(n=6)$ or behaviorally-tested rats infused with control+veh $(n=15)$, control+FGIN $(n=15)$, PXR AS-ODN+veh $(n=8)$, or PXR AS-ODN+FGIN $(n=13)$ in Experiment 2. Rats infused with PXR AS-ODN had a mean 1.8 fold lower PXR expression in the midbrain compared to control infusions in Experiment 2 (data not shown). (B) Depicts the mean ( \pm s.e.m.) $3 \alpha, 5 \alpha-$ THP levels in the midbrain of ovariectomized (OVX) estradiol (E2)-primed non tested rats infused with control+veh $(n=5)$, control+FGIN $(n=6)$, PXR AS-ODN+veh $(n=5)$, PXR AS-ODN+FGIN $(n=5)$, or behaviorally-tested rats infused with control+veh $(n=8)$, control+FGIN $(n=7)$, PXR AS-ODN+veh $(n=7)$, or PXR AS-ODN+FGIN $(n=6)$ in Experiment 3. Rats infused with PXR AS-ODN had a mean 1.5 fold lower PXR expression in the midbrain compared to control infusions in Experiment 3 (data not shown). (C) Depicts the mean ( \pm s.e.m.) $3 \alpha, 5 \alpha-$ THP levels in the midbrain of OVX/adrenalectomized (ADX), E2-primed rats that were non tested and infused with control+veh $(n=6)$, control+FGIN $(n=5)$, PXR AS-ODN+veh $(n=5)$, PXR AS-ODN+FGIN $(n=5)$, or behaviorally-tested and infused with control+veh $(n=9)$, control+FGIN $(n=5)$, PXR AS-ODN+veh $(n=8)$, or PXR AS-ODN+FGIN $(n=5)$ in Experiment 4. Rats infused with PXR AS-ODN had a mean 1.4 fold lower PXR expression in the midbrain compared to control infusions in Experiment 4 (data not shown). *above a line indicates a significant effect of PXR AS-ODNs compared to control. **above a line indicates significant effect of testing compared to non-tested rats $(P<0.05)$.

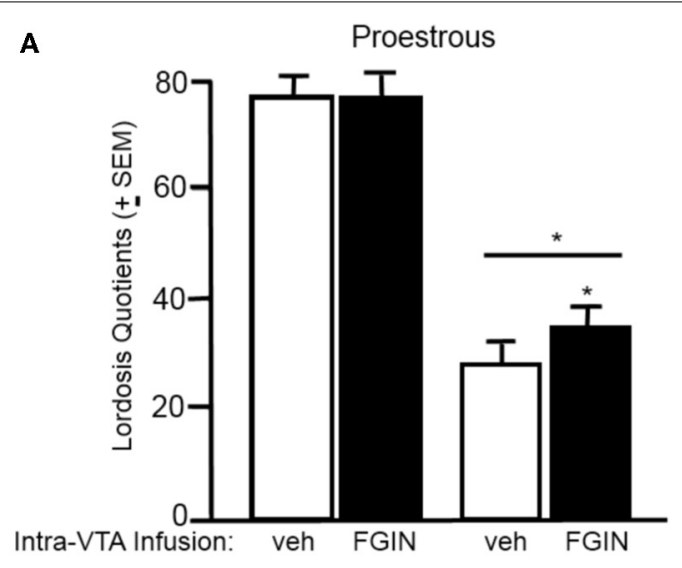

Intra-VTAAS-ODN: CONTROL PXRAS-ODN
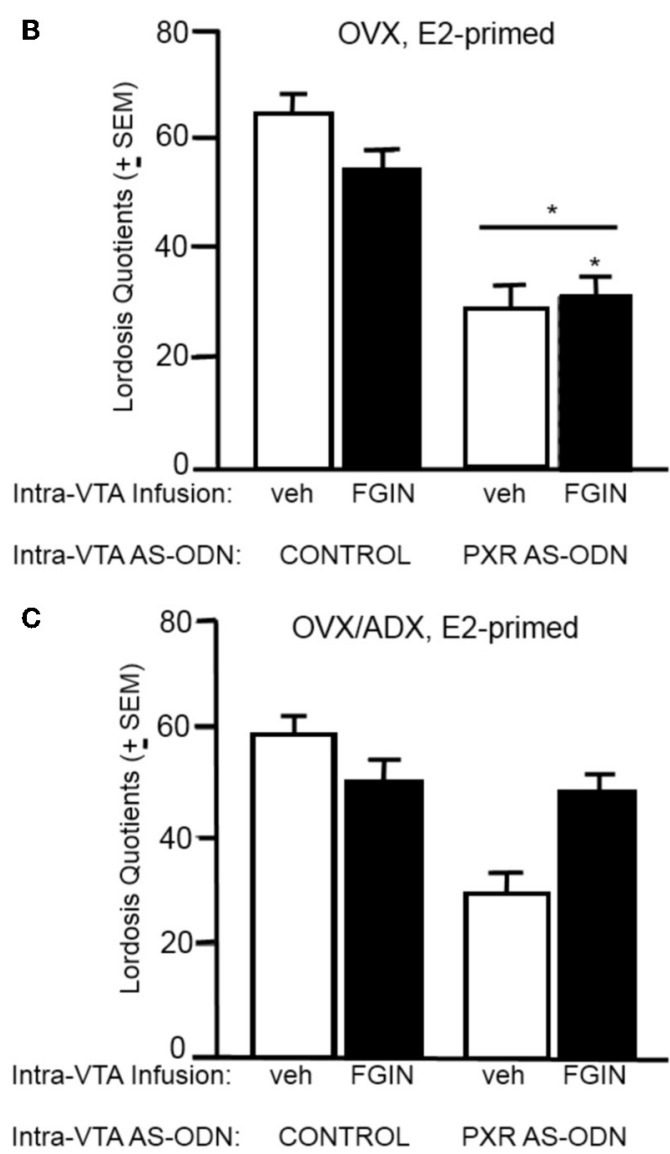

FIGURE 4 | (A) Depicts the mean ( \pm s.e.m.) lordosis quotients of proestrous rats infused with control and vehicle (veh, $n=15)$, control+FGIN ( $n=15)$, pregnane xenobiotic receptor (PXR) antisense deoxynucleotides (AS-ODNs) + vehicle $(n=8)$, or PXR AS-ODN+FGIN $(n=13)$ in Experiment 2. (B) Depicts the mean ( \pm s.e.m.) lordosis quotients of ovariectomized (OVX) estradiol (E2)-primed rats infused with control+veh $(n=8)$, control+FGIN ( $n=7)$, PXR AS-ODN+veh $(n=7)$, or PXR

AS-ODN+FGIN $(n=6)$ in Experiment 3. (C) Depicts the mean ( \pm s.e.m.) lordosis quotients of OVX/adrenalectomized (ADX), E2-primed rats infused with control+veh $(n=9)$, control+FGIN $(n=5)$, PXR AS-ODN+veh $(n=8)$, or PXR AS-ODN+FGIN $(n=5)$ in Experiment 4. *above a line indicates a significant effect of PXR AS-ODNs compared to control. $(P<0.05)$. 
infused with PXR AS-ODNs had lower levels compared to control infusions.

\section{Lordosis quotients (Figure 4C)}

There was main effect of PXR AS-ODN condition $\left[F_{(1,25)}=5.8\right.$, $P=0.02]$ for lordosis quotients, such that infusions of PXR ASODN decreased lordosis quotients compared to control infusions; effects of FGIN infusions did not reach statistical significance.

\section{Aggression quotients (Table 1)}

There was main effect of PXR AS-ODN condition $\left[F_{(1,25)}=\right.$ $4.9, P=0.03$ ] for aggression quotients, such that infusions of PXR AS-ODN decreased aggression quotients compared to control infusions; effects of FGIN infusions did not reach statistical significance.

\section{DISCUSSION}

The data support, in part, the hypothesis tested that PXR is an upstream factor of TSPO for neurosteroidogenesis of $3 \alpha, 5 \alpha-$ THP in the VTA for lordosis, independent of peripheral glands. First, proestrous rats administered a TSPO blocker (PK11195), subsequent to AS-ODNs to the VTA, had lower $3 \alpha, 5 \alpha$-THP levels in the midbrain and lordosis; the effects on lordosis could be reversed with replacement with $3 \alpha, 5 \alpha$-THP administration alone, but not when co-administered with PXR AS-ODN. Second, proestrous, OVX, or OVX/ADX rats infused with a TSPO enhancer (FGIN 1-27), subsequent to AS-ODNs to the VTA, had lower $3 \alpha, 5 \alpha$-THP levels in the midbrain and lordosis particularly among proestrous rats, compared to those that were OVX or OVX/ADX. Comparisons with removal of the main peripheral sources of steroids, ovaries and adrenals, were completed to address the role of PXR and TSPO for steroid synthesis in the brain. These data with a greater response in proestrous compared to rats with glands surgically removed suggest that there is not complete independence of these peripheral sources for PXR's actions in the midbrain VTA, which are likely upstream of TSPO. Thus, PXR may be acting as a homeostatic regulator, upstream of TSPO in the pathway for production of $3 \alpha, 5 \alpha-$ THP in the midbrain VTA, and behavioral responses of female rats.

The present data confirm the importance of PXR in the midbrain for $3 \alpha, 5 \alpha$-THP and lordosis. Inhibiting PXR with the same AS-ODN approach used here reduces $3 \alpha, 5 \alpha$-THP in the midbrain VTA concomitant with reductions in lordosis and enhancements in aggressive responding toward males during paced mating of proestrous rats, or those that were OVX and estradiol-primed (Frye et al., 2013, 2014). Additionally, activating PXR with ligands infused to the midbrain VTA enhances reproductive responding of female rats (Frye, 2011). Moreover, the present data confirm the role of biosynthesis of $3 \alpha, 5 \alpha$-THP from cholesterol in the midbrain VTA for lordosis. Inhibitors of TSPO, as well as downstream factors involved in biosynthesis, StAR or P450scc, infused to the midbrain VTA of female rats attenuates progestogenfacilitated lordosis (Petralia et al., 2005; Frye et al., 2008a; Frye, 2009; Frye and Paris, 2011). An opposite effect is observed with TSPO agonist, such as FGIN, when infused to the midbrain VTA as was observed here (Frye et al., 2009; Frye and Paris, 2011).
It should be noted that FGIN infusions in this study did not produce the same pattern of reduction for $3 \alpha, 5 \alpha$-THP levels in the midbrain as was observed in lordosis quotients. A consideration is that this experiment was conducted in proestrous rats, with peripheral sources of steroids, as well as typical steroid feedback mechanisms in place; a more robust response may have been observed with this FGIN dosing in OVX and/or OVX/ADX rats. Another consideration is that comparisons with non-tested rats in this experiment may have provided an indication of matinginduced $3 \alpha, 5 \alpha$-THP production from metabolism of progesterone from the ovaries, which could account for little difference in $3 \alpha, 5 \alpha$-THP levels in the midbrain after mating, albeit low lordosis responding with this manipulation. A third consideration is that measurement of dihydroprogesterone, or other steroids, were not assessed in the midbrain. Indeed, in the group that was co-administered PK11195 and $3 \alpha, 5 \alpha$-THP, the enhancements in lordosis were more robust than post-mating levels of $3 \alpha, 5 \alpha-$ THP on the midbrain that were measured; whether this could have been due to back-conversion of administered $3 \alpha, 5 \alpha$-THP or $3 \alpha, 5 \alpha$-THP from other sources is not known. Together, these data extends previous findings to suggest that PXR, which is known to act as a transcription factor for P450 enzymes involved in steroid metabolism, such as CYP11A1 (Ma et al., 2008; Zhang et al., 2008), may be another important neuroregulatory factor in the biosynthesis of $3 \alpha, 5 \alpha$-THP in the midbrain, upstream of TSPO, and resulting actions on lordosis in the adult. Moreover, the data that there were differences between proestrous, OVX, and OVX/ADX rats suggest that biosynthesis in the brain, as well as metabolism from peripheral sources of progesterone, are involved in PXR's modulation of $3 \alpha, 5 \alpha-$ THP. Alternatively, the removal of the glands disrupts multiple negative feedback loops of steroids, and thereby disrupts typical responses to steroids for behavior. We have observed that effects of PXR AS-ODN infusions to reduce lordosis and $3 \alpha, 5 \alpha$-THP levels in the midbrain of OVX rats only when they were estradiol-primed (Frye et al., 2014). Thus, hormonal milieu provides a significant context for interactions between neuroendocrine and behavioral responses.

The pattern of results here confirms prior studies showing a greater influence of PXR knockdown in the midbrain for behavior in the paced mating task, compared to the other behavioral tasks assessed (even when the order of testing in these tasks is altered as in Frye et al., in press). There were very few animals that received infusions outside the targeted area, and all experimental groups were not represented. The data from these subjects suggest that manipulations to other midbrain sites (e.g., substantia nigra, or central gray) did not produce the same pattern of effects as did infusions to the VTA, but rather produced responses similar to the control groups. Manipulations of $3 \alpha, 5 \alpha$-THP from exposure to mating, or infusions of $3 \alpha, 5 \alpha$-THP directly to this the midbrain (but not substantia nigra or central gray), increase levels of $3 \alpha, 5 \alpha$-THP in corticolimbic structures and reduce anxiety-like responding; however, manipulations of PXR typically produce less robust effects on these other measures, as was observed here. A question for future studies is the expression patterns and actions of PXR beyond the midbrain for reproduction-relevant behaviors, such as cognition, exploration, anxiety, and interactions with conspecifics. Mating-induced neurosteroidogenesis 
occurs beyond the midbrain to the hippocampus, cortex, and striatum (Frye and Rhodes, 2006; Frye et al., 2009). Indeed, we have observed that manipulating PXR in the midbrain of proestrous rats reduces $3 \alpha, 5 \alpha$-THP levels in the midbrain and the hippocampus, as well as a growth factor (brain-derived neurotrophic factor; BDNF) in the hippocampus (Frye et al., 2013, in press). It is plausible that PXR is having effects beyond those involving progestogen-facilitated lordosis through actions in the midbrain.

Beyond facilitating successful mating, progestogens are considered to have organizing effects on the nervous system during gestation/perinatally to influence later adult behaviors that ultimately are adaptive (reducing stress/anxiety, enhancing cognition, and conferring protection to neural insults/aging; Frye, 2009; Brinton, 2013; Brunton et al., 2014; Bali and Jaggi, 2014). We have focused on using lordosis as a bioassay to understand progestogens' mechanisms and effects in the central nervous system; albeit, other models support a role of progestogens for motivated, and cognitive processes. One example is mating-induced conditioned placed preference, where females will change their initial preference to spend time in a context associated with mating (González-Flores et al., 2004; Camacho et al., 2009; Arzate et al., 2011). Beneficial effects of progesterone or $3 \alpha, 5 \alpha$-THP administration to ovariectomized rats or mice has been described for spatial and object recognition memory tasks (Sandstrom and Williams, 2001; Tanabe et al., 2004; Walf et al., 2006; Frye et al., 2007, 2013). Furthermore, the capacity for de novo steroid synthesis in the prefrontal cortex and hippocampus (Cheng and Karavolas, 1975; Li et al., 1997; Furukawa et al., 1998; Frye, 2001a,b) suggests that PXR may also be a factor to investigate systematically in these regions for behaviors that contribute to successful mating. For example, in recent studies assessing the requirement of PXR for mating-induced $3 \alpha, 5 \alpha$-THP synthesis in the midbrain and the hippocampus, knocking down PXR attenuated effects of paced mating experience to increase $3 \alpha, 5 \alpha$-THP in these regions, as well as increase BDNF in the hippocampus, of proestrous rats (Frye et al., in press). Given the role of progestogens throughout the lifespan, the importance of PXRmediated $3 \alpha, 5 \alpha$-THP production and other measures of neural plasticity (e.g., BDNF) and behavioral plasticity (e.g., mating) are of continued interest.

In addition to further understanding potential downstream factors, such as TSPO and BDNF, the contributory role of other "liver" factors in the same nuclear receptor super family as PXR, such as liver X receptor (LXR), for neural and behavioral plasticity needs to be explored. Although the present experiment focused on the role of PXR, it would be of interest to consider the respective roles of these factors, which were first described in the liver, but both have received a greater focus on their effects in the nervous system more recently (Mellon et al., 2008). One focus of the effects of these receptors is their role in cholesterol clearance, which is related to diet and cardiovascular function, as well as important for neurodegenerative disorders, such as Alzheimer's disease, and neurodevelopmental disorders, such as Niemann-Pick disease (Whitney et al., 2002; Repa et al., 2007; Ma et al., 2008; Tang et al., 2008). As one example, mouse models of Niemann-Pick disease show deficits in cholesterol metabolism and $3 \alpha, 5 \alpha$-THP production in the brain, and such deficits could be reversed with administration of PXR ligands, one of them being 3 $\alpha, 5 \alpha$-THP (Frye and Rhodes, 2006; Frye, 2009; Brinton, 2013).

Early developmental effects of LXR in the brain have also been described. For example, protective effects similar to those described for PXR have been noted with LXR modulation in a Niemann-Pick disease mouse model (Repa et al., 2007) as well as promoting neurosteroidogenesis and protective effects in animal models of diabetic neuropathy and multiple sclerosis (Cermenati et al., 2010, 2012; Mitro et al., 2012). As well, the role of LXR in typical neurodevelopmental processes, such as neurogenesis, in the VTA of mice, using an in vitro model, has been recently described (Theofilopoulos et al., 2013). Additionally, knockout of the beta form of LXR that is highly expressed in the central nervous system increases anxiety-like responding of female mice and alters GABA in the cortex (Tan et al., 2012). In the present study, the role of PXR in the VTA for $3 \alpha, 5 \alpha$-THP production from cholesterol and subsequent behavioral effects was assessed. A consideration for future studies is elucidating how PXR and LXR may act synergistically for efficient cholesterol metabolism and clearance in neurons and glia, respectively, supporting neural and behavioral plasticity. Another important question is the role of PXR for neurosteroidogenesis in males; production of androstane neurosteroids, such as $3 \alpha$-androstanediol, occurs after mating of male rodents and has robust behavioral actions (Edinger and Frye, 2007; Frye et al., 2008b). Although proestrous female rats have higher expression of PXR in the midbrain than do males (Frye et al., 2013), the expression of PXR in males and females in other brain regions with high capacity for neurosteroidogenesis is not completely known. Together, these results involving liver factors, such as PXR, substantiate further studies of an interaction between peripheral and brain factors for behavior.

In summary, inhibiting TSPO with PK11195 reduced $3 \alpha, 5 \alpha-$ THP levels in the midbrain and lordosis, an effect that could be reversed with $3 \alpha, 5 \alpha$-THP administration, but not ASODN $+3 \alpha, 5 \alpha$-THP. PXR AS-ODNs blocked actions of FGIN 1-27 for lordosis and $3 \alpha, 5 \alpha$-THP levels among proestrous > OVX > OVX/ADX rats. Together, these data suggest the liver factor, PXR, may be upstream of TSPO, acting as a homeostatic regulator involved in neurosteroidogenesis of $3 \alpha, 5 \alpha$-THP in the brain for behavior. Understanding these basic mechanisms of how steroids are involved, and what factors are necessary for their production, for behavioral/neural plasticity supports future work on how a prominent peripheral factor, such as PXR, may have actions in the brain and, ultimately, find use in brain augmentation approaches.

\section{AUTHOR CONTRIBUTIONS}

All authors on this paper substantially contributed to the work described herein. Carolyn J. Koonce was involved in acquisition, analysis, and interpretation of data, and drafting of figures for paper and Results and Methods section. Alicia A.Walf was involved in acquisition, analysis, and interpretation of data, and drafting and revising of all sections of the paper. Cheryl A. Frye was involved in the conception and study design, acquisition, analysis, and interpretation of data, reviewing drafts of the work, and giving final approval of the paper to be submitted. 


\section{ACKNOWLEDGMENTS}

This research was supported by grants from the National Institute of Mental Health (MH0676980; RMH067698B). Technical assistance, provided by Drs. Paris and Rusconi, and Anthony Santarelli, Jennifer Torgersen, and Zhenhong Zhao, is greatly appreciated. Experiments described herein comply with the current laws of the United States. All authors report that they have no conflicts of interest (financial or otherwise) that would bias them to the outcome of these experiments.

\section{REFERENCES}

Acosta, S. A., Tajiri, N., Shinozuka, K., Ishikawa, H., Grimmig, B., Diamond, D., et al. (2013). Long-term upregulation of inflammation and suppression of cell proliferation in the brain of adult rats exposed to traumatic brain injury using the controlled cortical impact model. PLoS ONE 8:e53376. doi: 10.1371/journal.pone.0053376

Agís-Balboa, R. C., Pinna, G., Pibiri, F., Kadriu, B., Costa, E., and Guidotti, A. (2007). Down-regulation of neurosteroid biosynthesis in corticolimbic circuits mediates social isolation-induced behavior in mice. Proc. Natl. Acad. Sci. U.S.A. 104, 18736-18741. doi: 10.1073/pnas.0709419104

Arzate, D. M., Portillo, W., Rodríguez, C., Corona, R., and Paredes, R. G. (2011). Extended paced mating tests induces conditioned place preference without affecting sexual arousal. Horm. Behav. 59, 674-680. doi: 10.1016/j.yhbeh.2010.08.016

Azcoitia, I., Sierra, A., Veiga, S., and Garcia-Segura, L. M. (2003). Aromatase expression by reactive astroglia is neuroprotective. Ann. N. Y. Acad. Sci. 1007, 298-305. doi: 10.1196/annals. 1286.028

Bali, A., and Jaggi, A. S. (2014). Multifunctional aspects of allopregnanolone in stress and related disorders. Prog. Neuropsychopharmacol. Biol. Psychiatry 48, 64-78. doi: 10.1016/j.pnpbp.2013.09.005

Barbaccia, M. L., Serra, M., Purdy, R. H., and Biggio, G. (2001). Stress and neuroactive steroids. Int. Rev. Neurobiol. 246, 243-272. doi: 10.1016/S00747742(01)46065-X

Bauer, B., Hartz, A. M., Fricker, G., and Miller, D.S. (2004). Pregnane X receptor up-regulation of P-glycoprotein expression and transport function at the bloodbrain barrier. Mol. Pharmacol. 66, 413-419. doi: 10.1124/mol.66.3

Bauer, B., Yang, X., Hartz, A. M., Olson, E. R., Zhao, R., Kalvass, J. C., et al. (2006). In vivo activation of human pregnane $\mathrm{X}$ receptor tightens the blood-brain barrier to methadone through P-glycoprotein up-regulation. Mol. Pharmacol. 70, 1212-1219. doi: 10.1124/mol.106.023796

Billeci, A., Caso, V., Paciaroni, M., Palmerini, F., and Agnelli, G. (2007). Hormonereplacement therapy, dementia and stroke. Womens Health 3, 699-710. doi: 10.2217/17455057.3.6.699

Bitran, D., Foley, M., Audette, D., Leslie, N., and Frye, C. A. (2000). Activation of peripheral mitochondrial benzodiazepine receptors in the hippocampus stimulates allopregnanolone synthesis and produces anxiolytic-like effects in the rat. Psychopharmacology 151, 64-71. doi: 10.1007/s002130000471

Brinton, R. D. (2013). Neurosteroids as regenerative agents in the brain: therapeutic implications. Nat. Rev. Endocrinol. 9, 241-250. doi: 10.1038/nrendo.2013.31

Brunton, P. J., Russell, J. A., and Hirst, J. J. (2014). Allopregnanolone in the brain: Protecting pregnancy and birth outcomes. Prog. Neurobiol. 113, 106-136. doi: 10.1016/j.pneurobio.2013.08.005

Camacho, F. J., García-Horsman, P., and Paredes, R. G. (2009). Hormonal and testing conditions for the induction of conditioned place preference by paced mating. Horm. Behav. 56, 410-415. doi: 10.1016/j.yhbeh.2009. 07.007

Cermenati, G., Abbiati, F., Cermenati, S., Brioschi, E., Volonterio, A., Cavaletti, G., et al. (2012). Diabetes-induced myelin abnormalities are associated with an altered lipid pattern: protective effects of LXR activation. J. Lipid Res. 53, 300-310. doi: 10.1194/jlr.M021188

Cermenati, G., Giatti, S., Cavaletti, G., Bianchi, R., Maschi, O., Pesaresi, M., et al. (2010). Activation of the liver $\mathrm{X}$ receptor increases neuroactive steroid levels and protects from diabetes-induced peripheral neuropathy. J. Neurosci. 30, 11896-11901. doi: 10.1523/JNEUROSCI.1898-10.2010

Chen, J., Chopp, M., and Li, Y. (1999). Neuroprotective effects of progesterone after transient middle cerebral artery occlusion in rat. J. Neurol. Sci. 171, 24-30. doi: 10.1016/S0022-510X(99)00247-6
Cheng, Y. J., and Karavolas, H. J. (1975). Subcellular distribution and properties of progesterone (delta4-steroid) 5a-reductase in rat medial basal hypothalamus. J. Biol. Chem. 250, 7997-8003.

Dussault, I., and Forman, B. M. (2002). The nuclear receptor PXR: a master regulator of "homeland" defense. Crit. Rev. Eukaryot. Gene Expr. 12, 53-64. doi: 10.1615/CritRevEukaryotGeneExpr.v12.i1.30

Edinger, K. L., and Frye, C. A. (2007). Sexual experience of male rats influences anxiety-like behavior and androgen levels. Physiol. Behav. 92, 443-453. doi: 10.1016/j.physbeh.2007.04.018

Erskine, M. S. (1985). Effects of paced coital stimulation on estrus duration in intact cycling rats and ovariectomized and ovariectomized-adrenalectomized hormone-primed rats. Behav. Neurosci. 99, 151-161. doi: 10.1037/07357044.99.1.151

Francis, G. A., Fayard, E., Picard, F., and Auwerx, J. (2002). Nuclear receptors and the control of metabolism. Annu. Rev. Physiol. 65, 261-311. doi: 10.1146/annurev.physiol.65.092101.142528

Frye, C. A. (2001a). The role of neurosteroids and nongenomic effects of progestins in the ventral tegmental area in mediating sexual receptivity of rodents. Horm. Behav. 40, 226-233. doi: 10.1006/hbeh.2001.1674

Frye, C. A. (2001b). The role of neurosteroids and non-genomic effects of progestins and androgens in mediating sexual receptivity of rodents. Brain Res. Brain Res. Rev. 37, 201-222. doi: 10.1016/S0165-0173(01)00119-9

Frye, C. A. (2009). Neurosteroids' effects and mechanisms for social, cognitive, emotional, and physical functions. Psychoneuroendocrinology 34, S143-S161. doi: 10.1016/j.psyneuen.2009.07.005

Frye, C. A. (2011). Novel substrates for, and sources of, progestogens for reproduction. J. Neuroendocrinol. 23, 961-973. doi: 10.1111/j.1365-2826.2011.02180.x

Frye, C. A., and Bayon, L. E. (1999). Mating stimuli influence endogenous variations in the neurosteroids $3 \alpha, 5 \alpha$-THP and $3 \alpha$-Diol. J. Neuroendocrinol. 11, 839-847. doi: 10.1046/j.1365-2826.1999.00379.x

Frye, C. A., Duffy, C. K., and Walf,A. A. (2007). Estrogens and progestins enhance spatial learning of intact and ovariectomized rats in the object placement task. Neurobiol. Learn. Mem. 88, 208-216. doi: 10.1016/j.nlm.2007.04.003

Frye, C. A., Koonce, C. J., Edinger, K. L., Osborne, D. M., and Walf, A. A. (2008b). Androgens with activity at estrogen receptor beta have anxiolytic and cognitive-enhancing effects in male rats and mice. Horm. Behav. 54, 726-734. doi: 10.1016/j.yhbeh.2008.07.013

Frye, C. A., Koonce, C. J., and Walf, A. A. (2014). Role of pregnane xenobiotic receptor in the midbrain ventral tegmental area for estradiol- and $3 \alpha, 5 \alpha$-THPfacilitated lordosis of female rats. Psychopharmacology. doi: 10.1007/s00213013-3406-0. [Epub ahead of print].

Frye, C. A., Koonce, C. J., and Walf, A. A. (in press). Involvement of pregnane xenobiotic receptor in mating-induced allopregnanolone formation in the midbrain and hippocampus and brain-derived neurotrophic factor in the hippocampus among female rats. Psychopharmacology. doi: 10.1007/s00213014-3569-3

Frye, C. A., Koonce, C. J., Walf, A. A., and Rusconi, J. C. (2013). Motivated behaviors and levels of $3 \alpha, 5 \alpha$-THP in the midbrain are attenuated by knocking down expression of pregnane xenobiotic receptor in the midbrain ventral tegmental area of proestrous rats. J. Sex. Med. 10, 1692-1706. doi: 10.1111/ jsm. 12173

Frye, C. A., and Paris, J. J. (2011). Progesterone turnover to its $5 \alpha$-reduced metabolites in the ventral tegmental area of the midbrain is essential for initiating social and affective behavior and progesterone metabolism in female rats. J. Endocrinol. Invest. 34, e188-e199. doi: 10.3275/7334

Frye, C. A., Paris, J. J., and Rhodes, M. E. (2008a). Exploratory, anti-anxiety, social, and sexual behaviors of rats in behavioral estrus is attenuated with inhibition of $3 \alpha, 5 \alpha$-THP formation in the midbrain ventral tegmental area. Behav. Brain Res. 193, 269-276. doi: 10.1016/j.bbr.2008.06.005

Frye, C. A., Paris, J. J., and Rhodes, M. E. (2009). Increasing $3 \alpha, 5 \alpha$-THP following inhibition of neurosteroid biosynthesis in the ventral tegmental area reinstates anti-anxiety, social, and sexual behavior of naturally receptive rats. Reproduction 137, 119-128. doi: 10.1530/REP-08-0250

Frye, C. A., Paris, J. J., Walf, A. A., and Rusconi, J. C. (2012). Effects and mechanisms of $3 \alpha, 5 \alpha$,-THP on emotion, motivation, and reward functions involving pregnane xenobiotic receptor. Front. Neurosci. 195:136. doi: $10.3389 /$ fnins. 2011.00136

Frye, C. A., and Rhodes, M. E. (2006). Progestin concentrations are increased following paced mating in midbrain, hippocampus, diencephalon, and 
cortex of rats in behavioral estrus, but only in midbrain of diestrous rats. Neuroendocrinology 83, 336-347. doi: 10.1159/000096051

Frye, C. A., Rhodes, M. E., Petralia, S. M., Walf, A. A., Sumida, K., and Edinger, K. L. (2006). 3alpha-hydroxy-5alpha-pregnan-20-one in the midbrain ventral tegmental area mediates social, sexual, and affective behaviors. Neuroscience 138, 1007-1014. doi: 10.1016/j.neuroscience.2005.06.015

Frye, C. A., and Walf, A. A. (2008). Membrane actions of progestins at dopamine type 1-like and GABAA receptors involve downstream signal transduction pathways. Steroids 73, 906-913. doi: 10.1016/j.steroids.2008.01.020

Furukawa, A., Miyatake, A., Ohnishi, T., and Ichikawa, Y. (1998). Steroidogenic acute regulatory protein (StAR) transcripts constitutively expressed in the adult rat central nervous system: colocalization of StAR, cytochrome P-450SCC (CYP XIA1), and 3 $\beta$-hydroxysteroid dehydrogenase in the rat brain. J. Neurochem. 71 , 2231-2238. doi: 10.1046/j.1471-4159.1998.71062231.x

Geick, A., Eichelbaum, M., and Burk, O. (2001). Nuclear receptor response elements mediate induction of intestinal MDR1 by rifampin. J. Biol. Chem. 276, 14581-14587. doi: 10.1074/jbc.M010173200

González-Flores, O., Camacho, F. J., Domínguez-Salazar, E., Ramírez-Orduna, J. M., Beyer, C., and Paredes, R. G. (2004). Progestins and place preference conditioning after paced mating. Horm. Behav. 46, 151-157. doi: 10.1016/j.yhbeh.2004.02.006

Harmsen, S., Meijerman, I., Beijnen, J. H., and Schellens, J. H. (2007). The role of nuclear receptors in pharmacokinetic drug-drug interactions in oncology. Cancer Treat. Rev. 33, 369-380. doi: 10.1016/j.ctrv.2007.02.003

He, J., Hoffman, S. W., and Stein, D. G. (2004). Allopregnanolone, a progesterone metabolite, enhances behavioral recovery and decreases neuronal loss after traumatic brain injury. Restor. Neurol. Neurosci. 22, 19-31.

King, S. R., Manna, P. R., Ishii, T., Syapin, P. J., Ginsberg, S. D., Wilson, K., et al. (2002). An essential component in steroid synthesis, the steroidogenic acute regulatory protein, is expressed in discrete regions of the brain. J. Neurosci. 22, 10613-10620.

Kinsley, C. H., and Lambert, K. G. (2008). Reproduction-induced neuroplasticity: natural behavioural and neuronal alterations associated with the production and care of offspring. J. Neuroendocrinol. 20, 515-525. doi: 10.1111/j.13652826.2008.01667.x

Kliewer, S. A., Goodwin, B., and Willson, T. M. (2002). The nuclear pregnane X receptor: a key regulator of xenobiotic metabolism. Endocr. Rev. 23, 687-702. doi: 10.1210/er.2001-0038

Lambert, K. G., Berry, A. E., Griffins, G., Amory-Meyers, E., Madonia-Lomas, L., Love, G., et al. (2005). Pup exposure differentially enhances foraging ability in primiparous and nulliparous rats. Physiol. Behav. 84, 799-806. doi: 10.1016/j.physbeh.2005.03.012

Li, X., Bertics, P. J., and Karavolas, H. J. (1997). Regional distribution of cytosolic and particulate 5a-dihydroprogesterone 3a-hydroxysteroid oxidoreductases in female rat brain. J. Steroid Biochem. Mol. Biol. 60, 311-318. doi: 10.1016/S09600760(96)00195-1

Livak, K. J., and Schmittgen, T. D. (2001). Analysis of relative gene expression data using real-time quantitative PCR and the 2(-Delta Delta C(T)). Methods 25, 402-408. doi: 10.1006/meth.2001.1262

Ma, X., Idle, J. R., and Gonzalez, F. J. (2008). The pregnane X receptor: from bench to bedside. Expert Opin. Drug Metab. Toxicol. 4, 895-908. doi: 10.1517/17425255.4.7.895

Macbeth, A. H., and Luine, V. N. (2010). Changes in anxiety and cognition due to reproductive experience: a review of data from rodent and human mothers. Neurosci. Biobehav. Rev. 34, 452-467. doi: 10.1016/j.neubiorev.2009. 08.011

Maki, P. M., and Henderson, V. W. (2012). Hormone therapy, dementia, and cognition: the Women's Health Initiative 10 years on. Climacteric 15, 256-262. doi: 10.3109/13697137.2012.660613

Mellon, S. H., and Deschepper, C. F. (1993). Neurosteroid biosynthesis: genes for adrenal steroidogenic enzymes are expressed in the brain. Brain Res. 629, 283-292. doi: 10.1016/0006-8993(93)91332-M

Mellon, S. H., Gong, W., and Schonemann, M. D. (2008). Endogenous and synthetic neurosteroids in treatment of Niemann-Pick Type C disease. Brain Res. Rev. 57, 410-420. doi: 10.1016/j.brainresrev.2007.05.012

Mitro, N., Cermenati, G., Giatti, S., Abbiati, F., Pesaresi, M., Calabrese, D., et al. (2012). LXR and TSPO as new therapeutic targets to increase the levels of neuroactive steroids in the central nervous system of diabetic animals. Neurochem. Int. 60, 616-621. doi: 10.1016/j.neuint.2012.02.025
Murphy, S. J., Littleton-Kearney, M. T., and Hurn, P. D. (2002). Progesterone administration during reperfusion, but not preischemia alone, reduces injury in ovariectomized rats. J. Cereb. Blood Flow Metab. 22, 1181-1188. doi: 10.1097/00004647-200210000-00005

Ott, M., Fricker, G., and Bauer, B. (2009). Pregnane X receptor (PXR) regulates P-glycoprotein at the blood-brain barrier: functional similarities between pig and human PXR. J. Pharmacol. Exp. Ther. 329, 141-149. doi: 10.1124/jpet.108.149690

Papadopoulos, V., Baraldi, M., Guilarte, T. R., Knudsen, T. B., Lacapère, J. J., Lindemann, P., et al. (2006). Translocator protein (18kDa): new nomenclature for the peripheral-type benzodiazepine receptor based on its structure and molecular function. Trends Pharmacol. Sci. 27, 402-409. doi: 10.1016/j.tips.2006.06.005

Paris, J. J., and Frye, C. A. (2008). Estrous cycle, pregnancy, and parity enhance performance of rats in object recognition or object placement tasks. Reproduction 136, 105-115. doi: 10.1530/REP-07-0512

Paxinos, G., and Watson, C. (1986). The Rat Brain. New York, NY: Academic Press. Petralia, S. M., and Frye, C. A. (2005). In the ventral tegmental area picrotoxin blocks FGIN 1-27-induced increases in sexual behavior of rats and hamsters. Psychopharmacology 178, 174-182. doi: 10.1007/s00213-004-2001-9

Petralia, S. M., Jahagirdar, V., and Frye, C. A. (2005). Inhibiting biosynthesis and/or metabolism of progestins in the ventral tegmental area attenuates lordosis of rats in behavioural oestrus. J. Neuroendocrinol. 17, 545-552. doi: 10.1111/j.1365-2826.2005.01342.x

Pinna, G., Agis-Balboa, R. C., Pibiri, F., Nelson, M., Guidotti, A., and Costa, E. (2008). Neurosteroid biosynthesis regulates sexually dimorphic fear and aggressive behavior in mice. Neurochem. Res. 33, 1990-2007. doi: 10.1007/s11064-0089718-5

Pinna, G., and Rasmusson, A. M. (2012). Up-regulation of neurosteroid biosynthesis as a pharmacological strategy to improve behavioural deficits in a putative mouse model of post-traumatic stress disorder. J. Neuroendocrinol. 24, 102-116. doi: 10.1111/j.1365-2826.2011.02234.x

Purdy, R. H., Morrow, A. L., Moore, P. H. Jr., and Paul, S. M. (1991). Stress-induced elevations of gamma-aminobutyric acid type A receptor-active steroids in the rat brain. Proc. Natl. Acad. Sci. U.S.A. 88, 4553-4557. doi: 10.1073/pnas.88.10.4553

Repa, J. J., Li, H., Frank-Cannon, T. C., Valasek, M. A., Turley, S. D., Tansey, M. G., and Dietschy, J. M. (2007). Liver X receptor activation enhances cholesterol loss from the brain, decreases neuroinflammation, and increases survival of the NPC1 mouse. J. Neurosci. 27, 14470-14480. doi: 10.1523/JNEUROSCI.482307.2007

Roof, R. L., Duvdevani, R., and Stein, D. G. (1992). Progesterone treatment attenuates brain edema following contusion injury in male and female rats. Restor. Neurol. Neurosci. 4, 425-427.

Roof, R. L., Duvdevani, R., and Stein, D.G. (1993). Gender influences outcome of brain injury: progesterone plays a protective role. Brain Res. 607, 333-336. doi: 10.1016/0006-8993(93)91526-X

Rossouw, J. E., Anderson, G. L., Prentice, R. L., LaCroix, A. Z., Kooperberg, C., Stefanick, M. L., et al. (2002). Risks and benefits of estrogen plus progestin in healthy postmenopausal women: Principal results from the Women's Health Initiative randomized controlled trial. JAMA 288, 321-333. doi: 10.1001/jama.288.3.321

Sandstrom, N. J., and Williams, C. L. (2001). Memory retention is modulated by acute estradiol and progesterone replacement. Behav. Neurosci. 115, 384-393. doi: 10.1037/0735-7044.115.2.384

Schmittgen, T. D., and Livak, K. J. (2008). Analyzing real-time PCR data by the comparative $\mathrm{C}(\mathrm{T})$ method. Nat. Protoc. 3, 1101-1108. doi: 10.1038 /nprot.2008.73

Shapiro, S. (2006). Risk of cardiovascular disease in relation to the use of combined postmenopausal hormone therapy: detection bias and resolution of discrepant findings in two Women's Health Initiative studies. Climacteric 9, 416-420. doi: 10.1080/13697130601012061

Shumaker, S. A., Legault, C., Rapp, S. R., Thal, L., Wallace, R. B., Ockene, J. K., et al. (2003). Estrogen plus progestin and the incidence of dementia and mild cognitive impairment in postmenopausal women: the Women's Health Initiative Memory Study: a randomized controlled trial. JAMA 289, 2651-2662. doi: 10.1001/jama.289.20.2651

Tan, X. J., Dai, Y. B., Wu, W. F., Warner, M., and Gustafsson, J. A.. (2012). Anxiety in liver $\mathrm{X}$ receptor $\beta$ knockout female mice with loss of glutamic acid decarboxylase 
in ventromedial prefrontal cortex. Proc. Natl. Acad. Sci. U.S.A. 109, 7493-7498. doi: 10.1073/pnas.1205189109

Tanabe, F., Miyasaka, N., Kubota, T., and Aso, T. (2004). Estrogen and progesterone improve scopolamine-induced impairment of spatial memory. J. Med. Dent. Sci. 51, 89-98.

Tang, W., Ma, Y., Jia, L., Ioannou, Y. A., Davies, J. P., and Yu, L. (2008). Niemann-Pick C1-like 1 is required for an LXR agonist to raise plasma HDL cholesterol in mice. Arterioscler. Thromb. Vasc. Biol. 28, 448-454. doi: 10.1161/ATVBAHA.107.160465

Theofilopoulos, S., Wang, Y., Kitambi, S. S., Sacchetti, P., Sousa, K. M., Bodin, K., et al. (2013). Brain endogenous liver X receptor ligands selectively promote midbrain neurogenesis. Nat. Chem. Biol. 9, 126-133. doi: 10.1038/nchembio.1156

Toung, T. J., Chen, T. Y., Littleton-Kearney, M. T., Hurn, P. D., and Murphy, S. J. (2004). Effects of combined estrogen and progesterone on brain infarction in reproductively senescent female rats. J. Cereb. Blood Flow Metab. 24, 1160-1166. doi: 10.1097/01.WCB.0000135594.13576.D2

Uphouse, L., Adams, S., Miryala, C. S., Hassell, J., and Hiegel, C. (2013). RU486 blocks effects of allopregnanolone on the response to restraint stress. Pharmacol. Biochem. Behav. 103, 568-572. doi: 10.1016/j.pbb.2012.09.024

Uphouse, L., Selvamani, A., Lincoln, C., Morales, L., and Comeaux, D. (2005). Mild restraint reduces the time hormonally primed rats spend with sexually active males. Behav. Brain Res. 157, 343-350. doi: 10.1016/j.bbr.2004.08.001

Walf, A. A., Rhodes, M. E., and Frye, C. A. (2006). Ovarian steroids enhance object recognition in naturally cycling and ovariectomized, hormone-primed rats. Neurobiol. Learn. Mem. 86, 35-46. doi: 10.1016/j.nlm.2006.01.004

Whitney, K. D., Watson, M. A., Collins, J. L., Benson, W. G., Stone, T. M., Numerick, M. J., et al. (2002). Regulation of cholesterol homeostasis by the liver
$\mathrm{X}$ receptors in the central nervous system. Mol. Endocrinol. 16, 1378-1385. doi: 10.1210/mend.16.6.0835

Xu, D. X., Wei, W., Sun, M. F., Wei, L. Z., and Wang, J.P. (2005). Melatonin attenuates lipopolysaccharide-induced down-regulation of pregnane $\mathrm{X}$ receptor and its target gene CYP3A in mouse liver. J. Pineal Res. 38, 27-34. doi: 10.1111/j.1600-079X.2004.00171.x

Zhang, B., Xie, W., and Krasowski, M.D. (2008). PXR: a xenobiotic receptor of diverse function implicated in pharmacogenetics. Pharmacogenomics 9, 1695-1709. doi: 10.2217/14622416.9.11.1695

Conflict of Interest Statement: The authors declare that the research was conducted in the absence of any commercial or financial relationships that could be construed as a potential conflict of interest.

Received: 23 January 2014; accepted: 31 March 2014; published online: 21 April 2014. Citation: Frye CA, Koonce CJ and Walf AA (2014) The pregnane xenobiotic receptor, a prominent liver factor, has actions in the midbrain for neurosteroid synthesis and behavioral/neural plasticity of female rats. Front. Syst. Neurosci. 8:60. doi: 10.3389/ fnsys.2014.00060

This article was submitted to the journal Frontiers in Systems Neuroscience.

Copyright (c) 2014 Frye, Koonce and Walf. This is an open-access article distributed under the terms of the Creative Commons Attribution License (CC BY).

The use, distribution or reproduction in other forums is permitted, provided the original author(s) or licensor are credited and that the original publication in this journal is cited, in accordance with accepted academic practice. No use, distribution or reproduction is permitted which does not comply with these terms. 